\title{
Randomised double-blind trial of recombinant interferon-beta for condyloma acuminatum
}

\author{
J Monsonego, G Cessot, S E Ince, A R Galazka, A K Abdul-Ahad
}

\begin{abstract}
Objective: To evaluate the safety and efficacy of two intralesional doses of recombinant human interferon-beta (r-hIFN-beta: Rebif ${ }^{\circledR}$, Ares Serono), given 3 times a week for 3 weeks, in the treatment of condyloma acuminatum.

Design: A randomised, double-blind, within-patient, placebo-controlled study.

Subjects: 25 patients ( 24 males, 1 female) with a history of condyloma acuminatum. Twenty had failed previous treatment for condyloma acuminatum. In each patient, 3 distinct lesions were selected for treatment. Each selected lesion was randomly assigned to receive intralesionally one of the following: r-hIFN-beta 33,000 IU/day, r-hIFN-beta $1 \times 10^{6} \mathrm{IU} /$ day, or matching placebo.

Setting: Institut Alfred Fournier, Paris, France.

Outcome measures: Response was evaluated colposcopically at the end of treatment (day 22) and 5 weeks later (month 2). Complete response (CR) was defined as disappearance of the treated lesion. Partial response (PR) was defined as at least a $50 \%$ reduction in size, but not disappearance of the treated lesion.

Results: The higher dose of $1 \times 10^{6} \mathrm{IU}$ achieved significantly more complete and partial remissions than placebo, both by the end of treatment, and 5 weeks later.

Conclusions: r-hIFN-beta appears to be safe and effective when administered intralesionally to patients with condyloma acuminatum. Most of the treated patients had failed previous treatments and were therefore a resistant population.

(Genitourin Med 1996;72:111-114)
\end{abstract}

Keywords: Condyloma acuminatum; interferon; papilloma virus

\author{
Institut Alfred \\ Fournier, Paris, \\ France \\ J Monsonego \\ G Cessot \\ Ares-Serono SA, 1202 \\ Geneva, Switzerland \\ $S$ E Ince \\ A R Galazka \\ A K Abdul-Ahad \\ Correspondence to: \\ Joseph Monsonego, Institut \\ Alfred Fournier, 25, Bd \\ Saint-Jacques, 75014 Paris, \\ France. \\ Accepted for publication \\ 15 January 1996
}

\section{Introduction}

Human papilloma viruses (HPV) are now the most common sexually transmitted viral agents. ${ }^{1}$ The infections may be asymptomatic or may be manifested in various benign or malignant lesions, most noticeably anogenital condyloma acuminatum (genital warts) and anogenital carcinoma. ${ }^{23}$ The association of genital warts with cervical cancer is strong, independent of other risk factors and is consistent worldwide. ${ }^{4}$ Although HPV infection causes substantial morbidity, conventional therapy for genital warts has involved local destruction of warty tissue. This succeeds in clearing visible disease in most patients, although recurrences are frequent, probably owing to persistent subclinical infection. ${ }^{5}$ Clinical trials have demonstrated that the intralesional administration of different interferon (IFN) preparations is more effective than that of placebo. ${ }^{6-12}$ Promising results have been reported with both IFN-alpha and IFN-beta, but the effects of intralesionally administered $r$-hIFN-beta in the treatment of this disease have not been examined carefully in placebo-controlled trials. To determine the safety and efficacy of intralesionally administered $r$-hIFN-beta in the treatment of condyloma acuminatum, we conducted a randomised, double-blind, within-patient, placebo-controlled, dose-comparative study.

\section{Patients and methods}

We studied 25 patients, of whom 24 were male and one was female (aged 18-38 years; mean $24 \cdot 7$ ) with a mean history of condyloma acuminatum of 391 days. The majority (20) had undergone previous treatment for condyloma acuminatum. This ranged from 1 to 7 treatments for a total of 49 for the whole group, most of them by $\mathrm{CO}_{2}$ laser. The mean duration of disease in these patients was 482 days.

Eligibility criteria for inclusion included colposcopically diagnosed vaginal, vulval or perianal (women) or penile (men) condyloma acuminatum, with three or more distinct lesions in the vagina or vulval-perianal area (women), or on the penile shaft, foreskin, or glans (men). Lesions selected for treatment had to be of similar size ( $>3 \mathrm{~mm}$ in diameter), with a total area of $\leqslant 1 \mathrm{~cm}^{2}$, separated from each other by at least $1 \mathrm{~cm}$, preferably (but not necessarily) at the same site. None were located in the anal canal or distal urethra.

Patients with condylomatosis extending beyond the ano-genital area, or any invasive genital malignancy or any form of intraepithelial neoplasia of the genitals were also excluded.

The r-hIFN-beta, which was supplied by Ares-Serono, Aubonne, Switzerland, is glycosylated, being produced in genetically engineered Chinese hamster ovary cells, and consists of the native human IFN-beta amino acid sequence. It is essentially identical to natural IFN-beta in its physicochemical and biological properties. 
Statistical summary of colposcopic examination on study day 22 (D22) and at the end of month 2 (M2)

\begin{tabular}{|c|c|c|c|c|c|c|}
\hline & \multicolumn{2}{|c|}{ Placebo } & \multicolumn{2}{|c|}{$\begin{array}{l}\text { Rebif® } \\
33,000 \text { IU }\end{array}$} & \multicolumn{2}{|c|}{$\begin{array}{l}\text { Rebif® } \\
1 M I U\end{array}$} \\
\hline & $D 22$ & M2 & $D 22$ & M2 & $D 22$ & M2 \\
\hline $\begin{array}{l}\text { Success } \\
\text { (n and \%) }\end{array}$ & $\begin{array}{r}5 \\
21\end{array}$ & $\begin{array}{r}3 \\
13\end{array}$ & $\begin{array}{r}9 \\
38\end{array}$ & $\begin{array}{r}9 \\
39\end{array}$ & $\begin{array}{l}15 \\
63\end{array}$ & $\begin{array}{l}11 \\
48\end{array}$ \\
\hline $\begin{array}{l}\text { Failure } \\
\text { (n and \%) }\end{array}$ & $\begin{array}{l}19 \\
79\end{array}$ & $\begin{array}{l}20 \\
87\end{array}$ & $\begin{array}{l}15 \\
63\end{array}$ & $\begin{array}{l}14 \\
61\end{array}$ & $\begin{array}{r}9 \\
38\end{array}$ & $\begin{array}{l}12 \\
52\end{array}$ \\
\hline $\begin{array}{l}\text { \% reduction } \\
(\text { mean }(S D))\end{array}$ & $\begin{array}{c}36 \\
(45)\end{array}$ & $\begin{array}{c}18 \\
(68)\end{array}$ & $\begin{array}{c}58 \\
(45)\end{array}$ & $\begin{array}{c}51 \\
(56)\end{array}$ & $\begin{array}{c}83 \\
(31)\end{array}$ & $\begin{array}{c}65 \\
(46)\end{array}$ \\
\hline
\end{tabular}

In each patient, three distinct lesions were selected for treatment. Each selected lesion was randomly assigned to receive intralesionally one of the following: r-hIFN-beta $33,000 \mathrm{IU} /$ day, r-hIFN-beta $1 \times 10^{6} \mathrm{IU} /$ day, or matching placebo. This design has the following advantages: it eliminates inter-patient variability, results in equal numbers of treated lesions per treatment at each time point, and gives every patient the opportunity to receive active treatment.

In order to reduce the risk of re-infection during the study, sexually active patients were instructed to abstain from unprotected sexual intercourse during the entire study and were provided with condoms.

Injections were administered intralesionally, in a volume of $0.1 \mathrm{ml}$, under colposcopic control at a minimum depth of approximately 2 $\mathrm{mm}$, three times per week during a 19-day period. In all cases the injection was preceded by the administration of a local anaesthetic (lidocaine) to prevent pain on injection.

Response was evaluated colposcopically at the end of treatment (day 22) and 5 weeks later (month 2). Each lesion was measured directly in $\mathrm{mm}$ (that is, longest diameter and longest perpendicular diameter) and the area $\left(\mathrm{mm}^{2}\right)$ was calculated from the two measurements. Complete response (CR) was defined as disappearance of the treated lesion. Partial response (PR) was determined by reduction in size, but not disappearance of the treated lesion. Four degrees of PR were distinguished: $\mathrm{PR}_{\mathrm{a}}<25 \%$ reduction in lesion area; $\mathrm{PR}_{\mathrm{b}}>$

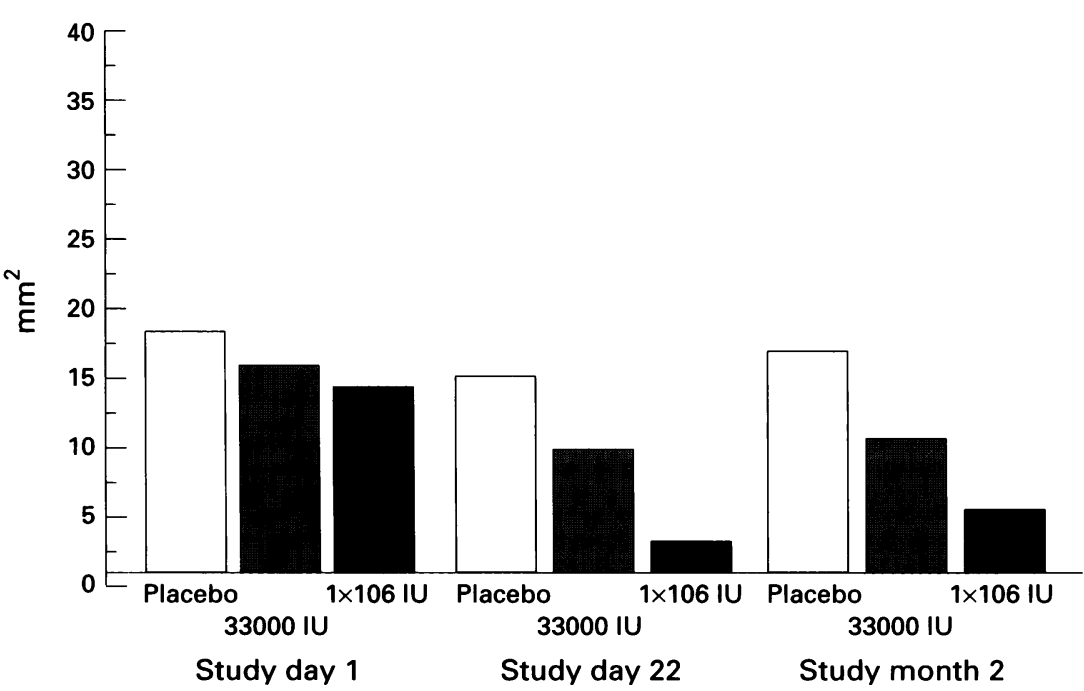

Figure 1 Mean areas of the lesions measured on Study Day 1, Study Day 22 and Study Month 2-All Patients Efficacy Analysis.
$25 \%$ but $<50 \%$ reduction; $\mathrm{PR}_{\mathrm{c}}>50 \%$ but $<$ $75 \%$; reduction; $\mathrm{PR}_{\mathrm{d}}>75 \%$ reduction. No response (NR) was recorded when there was no change, or an increase in size of the treated lesion. Relapse ( $R$ ), which was recorded only at the month 2 evaluation, was defined as recurrence or deterioration of $>25 \%$ of the treated lesion following improvement at d $\overline{\text { bे }}$ 22. Lesions not showing a complete response at the month 2 evaluation were subsequenty treated conventionally.

The McNemar test was utilised to test for treatment effect, lesions showing a comple response (CR) being considered as treatme $\mathrm{Et}$ successes, while those showing a partial (PI:) or no response (NR) were considered as treatment failures. The percentages of reduction the area of treated lesions were compared using the Quade test (an extension of the Wilcoxon signed-ranks test). In both tests the significance alpha level was 0.05 two sided.

\section{Results} the data from 24 were analysed for efficact The area of lesions treated by each of the three modalities were not significantly different $\overrightarrow{a t}$ baseline. One patient was a protocol violater and was therefore excluded from the efficacy analysis. At day 22, (table) a total of 72 lesions had been treated and observed. Of these $15 / 24(63 \%)$ of lesions injected with $1 \times 10^{6}$ IU r-hIFN-beta showed a CR, compared with $9 / 24(38 \%)$ and $5 / 24(21 \%)$ injected wi 33,000 IU r-hIFN-beta and placebo respe tively. The number of CRs resulting from the higher dose was significantly higher than thä $t$ resulting from treatment with placebo ( $\mathrm{p}=$ 0.0063, McNemar test, two-sided), while not significantly different from the lower dose ( $\mathrm{p}$ $0 \cdot 34, \mathrm{McNemar}$ test).

At the month 2 evaluation, (table) on patient did not return for follow-up examingtion. At this time, $11 / 23(48 \%)$ of lesious injected with $1 \times 10^{6} \mathrm{IU}$ r-h-IFN-bega showed a CR, compared with $9 / 23(39 \%)$ and $3 / 23$ (13\%) injected with 33,000 IU r-hIFI beta and placebo respectively. Again, the number of CRs resulting from treatment with the higher dose of r-hIFN-beta was signiff cantly higher than that resulting from placebf treatment ( $p=0.0078$, McNemar test).

Both on day 22 and month 2 , the number $\stackrel{\circ}{\circ}$ CRs resulting from treatment with 33,000 I r-hIFN-beta was not significantly different from placebo. However, there was a strorg dose-response relationship across the three treatments.

The comparison between the three trea ment groups of the reduction in area of the lesions on day 22 and month 2 (figs 1 \& 29 , was highly significant, $(\mathrm{p}=0.0035$, and 0.0088 respectively, Quade test $\left.{ }^{13}\right)$. On both occasions, only the reduction in area resulting from treatment with $1 \times 10^{6} \mathrm{IU}$ r-hIFN-beta, was significantly greater than that with placebo.

Of the 21 lesions treated with $1 \times 10^{6} \mathrm{IU}$ r-hIFN-beta and for which an improvement 


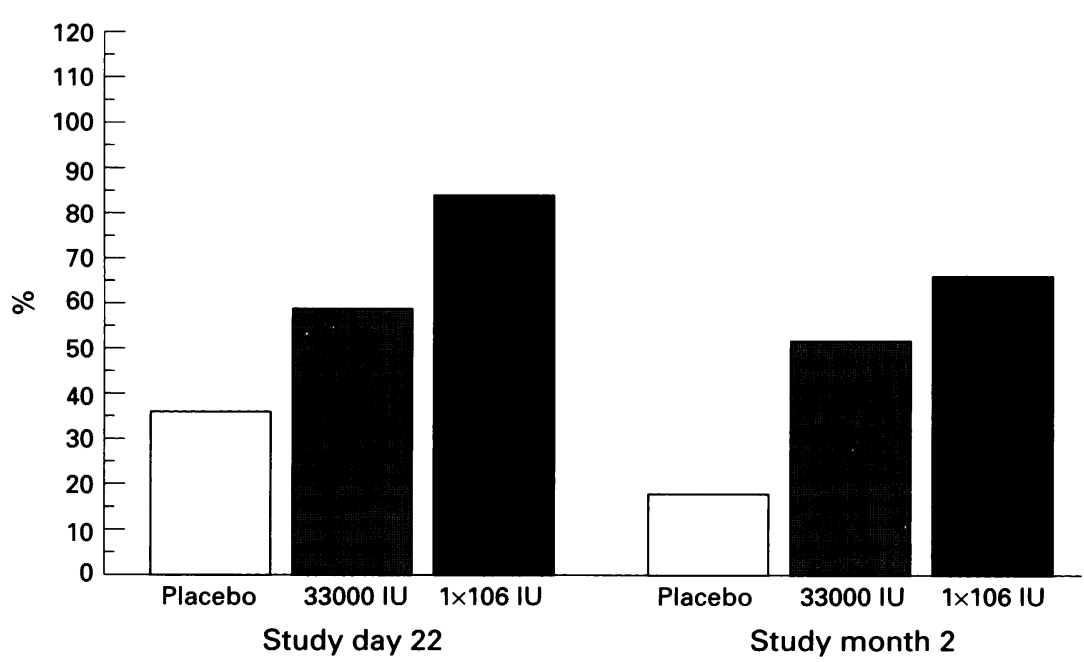

Figure 2 Mean reduction in area of the lesions observed on Study Day 22 and Study Month 2-All Patients Efficacy Analysis.

was observed on day $22\left(\mathrm{CR}+\mathrm{PR}_{\mathrm{a}}+\mathrm{PR}_{\mathrm{b}}+\right.$ $\left.P_{\mathrm{c}}+\mathrm{PR}_{\mathrm{d}}\right), 8(38 \%)$ relapsed by month 2 . Half of these lesions had shown a complete response, while the other half had exhibited partial responses. By the same criteria, 7 (54\%) of 13 lesions showing improvement on placebo treatment at day 22 , deteriorated at month 2 .

The treatment was well tolerated, the most common adverse events were flu-like symptoms. They were in general transient and mild.

\section{Discussion}

Although promising results have previously been reported following the use of interferons alpha and beta in the treatment of condyloma acuminatum, we have been unable to trace any other reported double-blind, placebocontrolled study of r-hIFN-beta. Cumulative data generated by a series of clinical trials have shown that human IFN-beta causes a regression of genital warts. A pilot study ${ }^{8}$ examined the effects of the injection of small doses $(300$ U) of human fibroblast IFN (natural IFNbeta) into genital warts, and suggested that IFN did inhibit wart growth, although it concluded that the dose was probably too small to have a dramatic effect.

A two-part trial was conducted to assess the value of fibroblast IFN in the treatment of condyloma acuminatum, ${ }^{14}$ this found that intramuscular injection was preferable to topical or intralesional administration. In the subsequent double-blind, placebo-controlled trial, the investigators found that intramuscular injections of hIFN-beta provided effective treatment of condyloma acuminatum, with an $80 \% \mathrm{CR}$ in 11 patients receiving the active preparation, compared with $20 \% \mathrm{CR}$ in the placebo group $(n=11)$. Subsequently, eight of the non-responders responded to open label IFN-beta. No recurrence was reported among responders during a 12 month follow-up period.

Recently, a randomised, double-blind, placebo-controlled trial involving 100 patients has demonstrated that systemically adminis- tered fibroblast IFN-beta, was effective in the long term eradication of anogenital condylomatous lesions. ${ }^{15}$ The dose used was $2 \times 10^{6}$ IU/day for 10 days, given intramuscularly. Fifty one per cent of patients treated with IFNbeta showed a complete response, compared to $29 \%$ of placebo treated patients $(\mathrm{p}<0.05)$.

All 24 patients who had responded to IFNbeta, remained lesion free at 1 year, while 12 of the 13 patients who had responded to placebo, had recurrent lesions, when followed up for the same period.

The use of intramuscular injections of IFNbeta was again investigated in a placebocontrolled study in 37 patients, classified according to site of lesion and HPV type. ${ }^{16}$ No association was apparent between response and whether the lesion was associated with HPV 6, HPV 11 or HPV 16. Satisfactory results were achieved in treating vulval and vaginal condylomata as well as HPV-CIN II lesions, but the success rate was less satisfactory for flat HPV lesions of the cervix, especially when associated with high-grade CIN.

Intralesional administration of natural IFNalpha was evaluated in an open study, ${ }^{9}$ in which $7 / 10$ patients had a significant reduction in the size of their lesions, while five of these experienced CR. No lesions that responded to IFN treatment recurred during a follow-up period of up to nine months.

A large $(n=296)$, randomised, doubleblind trial ${ }^{10}$ compared intralesional IFN-alpha$2 \mathrm{~b}\left(1 \times 10^{6} \mathrm{IU}\right.$, three times a week for three weeks) with placebo and found that IFN provided significantly better response $(P<$ 0.001 ), although the frequency of adverse effects led the investigators to conclude that IFN-alpha-2b was only fairly well tolerated. In similar studies ${ }^{17}$ authors found a complete disappearance of all warts in $43.8 \%$ of patients.

A randomised, double-blind, placebo-controlled trial of intralesional injections of natural IFN-alpha $\left(2.5-5.0 \times 10^{6} \mathrm{IU} / 25 \mathrm{~mm}^{2}\right.$ wart area, twice weekly for eight weeks or until all treated genital warts completely disappeared, whichever was less) involving 158 patients, found that the treatment completely eliminated warts in $62 \%$ of treated patients, compared with only $21 \%$ in the placebo group. ${ }^{12}$

When three different IFN preparations were compared in a placebo-controlled trial, ${ }^{12}$ rates of lesion clearance following intralesional injection of $1 \times 10^{6} \mathrm{IU}$ three times a week for four weeks were not significantly different between IFN-alpha-2a, natural IFN-alpha and natural IFN-beta. In another double-blind placebo-controlled study ${ }^{11}$ using subcutaneously administered IFN-alpha-2a, IFNalpha-2b and natural IFN-alpha, there was no significant difference between all IFN groups combined and placebo recipients in terms of CR or $75 \%$ clearance, although IFN appeared to be more effective than placebo in causing $\leqslant 50 \%$ lesion regression. Only natural IFNalpha produced significant beneficial effects at all levels of lesion clearance evaluated.

The mechanisms by which IFN-beta causes the disappearance of genital warts might be 
similar to those that lead to the elimination of extrachromosomal viral genomes from bovine papilloma virus transformed cells. ${ }^{18}$ They may include the inhibition of clonal growth of HPV infected cells, ${ }^{19}$ and the inhibitory TGF-beta1/IFN-beta cytokine pathway. ${ }^{20}$ The fact that the patients harbouring HIV were poor responders when interferon was used to treat genital warts ${ }^{21}$ suggests that an intact immune system is necessary for an effective curative effect of interferon.

The possibility of clearing the HPV genome from epidermal cells is supported by our finding that the majority of warts that had shown a complete response did not recur during follow up. A clinical trial with HPV typing will be needed to correlate the disappearance of visible warts with the persistence or resolution of subclinical HPV infection. The recurrence observed after traditional therapy is probably related to the persistence of the virus.

Given the above results and the recent availability of r-hIFN-beta, a double-blind, placebo-controlled trial to determine the role of this agent in condyloma acuminatum appeared timely. In terms of the difference in CR rates, the sample size yielded a $>90 \%$ power to detect improvement over placebo (two-tailed alpha $=0.05$ ).

It can be concluded that a dose of r-hIFNbeta $1 \times 10^{6} \mathrm{IU}$ per lesion is more effective than placebo at day 22 and month 2 , and is associated with an acceptable side-effect profile.

The published cure rates of condyloma acuminatum when using traditional treatment modalities (cytotoxic agents and cytoreductive therapies) vary widely between 10 to $90 \% .^{322} 23$ These figures were largely obtained by treating lesions that had not received previous therapy. All therapeutic modalities are associated with recurrence rates which can be up to $30 \%$. This is probably because none of the therapies is aimed at eliminating the source of infection (HPV).

In this study, the great majority $(80 \%)$ of patients had a resistant form of genital warts. Interferon-beta can eliminate the viral infection through its antiviral and immune potentiating activities. This could lead to lower recurrence rates than those associated with traditional therapies. Further experience could well demonstrate that the treatment of resistant genital warts with interferon-beta even when not curative might render re-treatment with traditional therapies more effective.
We thank Dr I Trinchard-Lugan for monitoring the study, and Dr PE Engrand for assisting in the interpretation of data. This trial was sponsored by a grant from Ares-Serono SA, 15 bis, chemin des Mines, 1202 Geneva, Switzerland.

1 Nuovo GJ, Blanco JS, Leipzig S, Smith D. Human papillomavirus detection in cervical lesions nondiagnostic for cervical intraepithelial neoplasia: correlation with Papanicolaou smear, colposcopy, and occurrence of cervical intraepithelial neoplasia. Obstet Gyncol 1990;75:1006-11.

2 Phelps WC, Alexander KA. Antiviral therapy for human papillomaviruses: Rationale and prospects. Ann Intern Med 1995;123:368-82.

3 Ferenczy A. Epidemiology and clinical pathophysiology of condylomata acuminata. Am f Obstet Gynecol 1995;172: 1331-39.

4 Bosch FX, Maños MM, Munoz N, et al. Prevalence of human papillomavirus in cervical cancer: a worldwide perhuman papillomavirus in cervical cancer: a

5 Ferenczy A, Mitao M, Nagau N, et al. Latent papillomavirus and recurring genital warts. $N$ Engl f Med 1985;313: 784-8.

6 Scott GM, Csonka GW. Effect of injections of small doses of human fibroblast interferon into genital warts: a pilot study. Br $\mathcal{F}$ Venereal Dis 1979;55:442-5.

7 Geffen JR, Klein RJ, Friedman-Klein AE. Intralesional administration of large doses of human leukocyte interferon for the treatment of condylomata acuminata. $\mathcal{F}$ Infect Dis 1984;150:612-5.

8 Eron LJ, Judson F, Tucker S, et al. Interferon therapy for condylomata acuminata. $N$ Engl $f$ Med 1986;315: 1059-64.

9 Vance JC, Bart BJ, Hansen RC, et al. Intralesional recombinant alpha-2 interferon for the treatment of patients with
condyloma acuminatum or verruca plantaris. Arch condyloma acuminatum

10 Friedman-Kien AE, Eron LJ, Conant $M$, et al. Natural interferon alfa for treatment of condylomata acuminata. $¥ A M A$ 1988;259:533-8.

11 Kirby $P$. Interferon in genital warts: much potential, modest progress. $¥ A M A$ 1988;259:570-2.

12 Reichman RC, Oakes D, Bonnez W, et al. Treatment of condylomata acuminatum with three different interferons administered intralesionally. Ann Intern Med 1988;108: 675-9.

13 Conover WI. Some methods based on ranks. In: Practical Nonparametric Statistics (2nd ed.). New York: Wiley J and Nonparametric Statistics

14 Schonfeld A, Nitke S, Schattner A, et al. Intramuscular human interferon-b injections in treatment of condyloma acuminata. Lancet 1984;I:1038-41.

15 Olmos L, Vilata J, Rodriguez Pichardo A, et al. Double-blind randomised clinical trial on the effect of interferon-beta in the treatment of condylomata acuminata. Int $\mathcal{F} S T D$ AIDS 1994;5:182-5.

16 Costa S, Poggi MG, Palmisano L, et al. Intramuscular binterferon treatment of human papillomavirus lesions in the lower female genital tract Cervix \& Lower Female Genital Tract 1984;6:203-12.

17 Welander Charles E, Homesley HD, Smiles KA, et al. Intralesional interferon alpha-2b for the treatment of genital lesional interferon alpha-2b for the trea

18 Turek LP, Byrne JC, Lowy DR, et al. Interferon induces morphologic reversion with elimination of extrachromosomorphologic reversion with elimination of extrachromoso-
mal viral genomes in bovine papillomavirus transformed mal viral genomes in bovine papillomavirus transform
mouse cells. Proc Natl Acad Sci USA 1982;79:7914-8.

19 Gangemi JD, Pirisi L, Angell M, et al. HPV replication in experimental models: effects on interferon. Antiviral Res 1994;24:175-90.

20 Aray I, Rady P, Tying SK. Interferon treatment enhances the expression of underphosphorylated (biologicallyactive) retinoblastoma protein in human papillomavirus infected cells through the inhibitory TGF-beta-1/IFN-beta cytokine pathway. Antiviral Res 1994;23:131-41.

21 Douglas JM, Rogers M, Judson FN. The effect of asymptomatic infection with HTLV-III on the response of genital matic infection with HTLV-III on the response of genital warts to intralesional treatment with

22 Handley J, Dinsmore W. Treatment of anogenital warts. $\Im$ Eur Acad Dermatol Venereol 1994;3:251-65.

23 Hatch KD. Clinical appearance and treatment strategies for human papillomavirus: a gynecologic perspective. Am $\mathcal{f}$ Obstet Gynecol 1995;172:1340-4. 